\title{
Cloning and Heterologous Expression of the Grecocycline Biosynthetic Gene Cluster
}

\author{
Oksana Bilyk ${ }^{1}$, Olga N. Sekurova ${ }^{2}$, Sergey B. Zotchev ${ }^{2}$, Andriy Luzhetskyy ${ }^{1,3 *}$ \\ 1 Helmholtz-Institute for Pharmaceutical Research Saarland, Saarland University Campus, Building C2.3, \\ 66123 Saarbrücken, Germany, 2 Department of Pharmacognosy, University of Vienna, 1090 Vienna, \\ Austria, 3 Universität des Saarlandes, Pharmazeutische Biotechnologie, Building C2.3, 66123 Saarbrücken, \\ Germany \\ * andriy.luzhetskyy @ helmholtz-hzi.de
}

\section{Abstract}

Transformation-associated recombination (TAR) in yeast is a rapid and inexpensive method for cloning and assembly of large DNA fragments, which relies on natural homologous recombination. Two vectors, based on $\mathrm{p} 15 \mathrm{a}$ and $\mathrm{F}$-factor replicons that can be maintained in yeast, $E$. coli and streptomycetes have been constructed. These vectors have been successfully employed for assembly of the grecocycline biosynthetic gene cluster from Streptomyces sp. Acta 1362. Fragments of the cluster were obtained by PCR and transformed together with the "capture" vector into the yeast cells, yielding a construct carrying the entire gene cluster. The obtained construct was heterologously expressed in S. albus J1074, yielding several grecocycline congeners. Grecocyclines have unique structural moieties such as a dissacharide side chain, an additional amino sugar at the $\mathrm{C}-5$ position and a thiol group. Enzymes from this pathway may be used for the derivatization of known active angucyclines in order to improve their desired biological properties.

Editor: Marie-Joelle Virolle, University Paris South, FRANCE

Received: May 13, 2016

Accepted: June 20, 2016

Published: July 13, 2016

Copyright: @ 2016 Bilyk et al. This is an open access article distributed under the terms of the Creative Commons Attribution License, which permits unrestricted use, distribution, and reproduction in any medium, provided the original author and source are credited.

Data Availability Statement: All relevant data are within the paper and its Supporting Information files.

Funding: This work was supported by the ERC starting grant EXPLOGEN No. 281623 to AL, https:// erc.europa.eu/. The funders had no role in study design, data collection and analysis, decision to publish, or preparation of the manuscript.

Competing Interests: The authors have declared that no competing interests exist.

\section{Introduction}

Actinomycete bacteria represent a rich source of secondary metabolites with diverse chemical scaffolds and interesting biological activities. $43 \%$ of biologically active compounds of microbial origin were isolated from actinomycetes, most of them from representatives of the genus Streptomyces known to be prolific secondary metabolite producers [1]. One of the approaches to exploit biosynthetic potential of actinomycetes involves the expression of orphan secondary metabolite gene clusters in heterologous host. Therefore, construction of vectors capable of carrying entire biosynthetic gene clusters is of high interest.

Nowadays, cosmid vectors are routinely used for genomic libraries constructions, and they can accommodate between $31 \mathrm{~kb}$ and $44 \mathrm{~kb}$ of foreign DNA [2]. However, gene clusters encoding secondary metabolites may reach over $100 \mathrm{~kb}$ in size, and cosmid vectors simply do not have a capacity to stably maintain such large DNA segments. There exist several alternative replicons capable of accommodating larger DNA insertions: p15a, RK2 and F1 (used for construction of BACs). p15a is a low copy (about 15 copies per chromosome) replicon from 
Escherichia coli [3]. Its utility in maintaining large DNA fragments was demonstrated in the assembly of a $62.4 \mathrm{~kb}$-large epothilone biosynthetic gene cluster [4]. RK2 replicons belong to the IncP incompatibility group and have been used for metagenomics library constructions [5]. Vectors constructed with RK2 replicon function in numerous Gram-negative bacterial species and have been transferred to Gram-positive bacteria, yeast and mammalian cells [6, 7]. Bacterial artificial chromosome (BACs) and P1 artificial chromosomes (PACs)-derived libraries are good alternatives to cosmid libraries when cloning of large DNA fragments is needed. PACs that combine features of BACs and bacteriophage $\mathrm{P} 1$ vectors can carry inserts ranging in size from $60 \mathrm{~kb}$ to $150 \mathrm{~kb}$, whereas BACs are capable of accommodating and propagating of DNA fragments up to $700 \mathrm{~kb}$ (with an average insert size $150 \mathrm{~kb}$ ). However, construction of BACderived libraries requires special equipment, is time-consuming, and expensive.

During the past years transformation-associated recombination (TAR) in yeast was successfully applied to assemble and clone large DNA fragments, including those harboring secondary metabolite gene clusters [8-11]. Originally, TAR method was developed for cloning of large genomic fragments without constructing and screening of genomic libraries [12]. This approach relies on homologous recombination between DNA of interest and short ( $\sim 0 \mathrm{bp})$ "capture arms" of the TAR-vector. Advantage of the method is elimination of in vitro enzymatic reactions such as restriction and ligation and reducing the amount of DNA handling. In addition, a recently published approach combining TAR-cloning and CRISPR/Cas9 system demonstrates a 15-fold recombination increase during TAR-assisted cloning of the human genes [13].

Herein, we report construction of specialized TAR-dedicated vectors, and successful assembly and heterologous expression of a 36-kb long grecocycline biosynthetic gene cluster (gre) using TAR method. Fragments of the gene cluster were obtained using PCR and transformed into Saccharomyces cerevisiae together with the "capture" vector, resulting in the construct carrying the entire gene cluster. The obtained construct was successfully expressed in S. albus, yielding several grecocycline congeners. Apparently, PCR-introduced mutations were responsible for the biosynthesis of these metabolites, suggesting that error-prone PCR combined with TAR assembly can be used for generation of new natural products' analogues.

\section{Methods and Materials}

\section{Strains, growth conditions and media}

For standard purposes S. sp. Acta 1362 and S. albus J1074-an S. albus G1 (DSM 41398) derivative with the defective SalGI restriction modification system, wild types and mutant were grown on $2 \%$ manitol and $2 \%$ soy bean meal, $\mathrm{pH} 7.5$, prepared as solid medium and tryptone soy broth (TS broth), prepared as liquid medium, at $280 \mathrm{C}$. For maintenance of $S$. albus pGRE apramycin was added to a final concentration of $50 \mu \mathrm{g} / \mathrm{ml}$. For production a liquid medium DNPM (4\% dextrin, $0,75 \%$ soytone, $0,5 \%$ baking yeasts and 2,1\% MOPS, pH 6.8 ) was used. DNA manipulations were carried out in Escherichia coli BG2005 and the non-methylating $E$. coli ET12567/pUZ8002 was used to drive conjugative transfer of non-methylated DNA to Actinobacteria as described previously [14]. E. coli strains were grown on Luria-Bertani agar or liquid medium containing appropriate antibiotic for selection.

\section{General genetic manipulation and standard PCR}

Standard molecular biology procedures were performed as described previously [2]. Isolation of plasmid DNA from E. coli and DNA restriction/ligation were performed by following the protocols of the manufacturers of the kits, enzymes, and reagents, Qiagen, Promega, NEB and Thermo Fisher Scientific. PCR reactions were performed by using Phusion High-Fidelity DNA 
polymerase (Thermo Fisher Scientific) for complementation and expression experiments and DreamTaq polymerase (Thermo Fisher Scientific) to verify mutants. Primers were purchased from Eurofins MWG Operon. The oligonucleotide primers that were used are listed in S1 Table. The oligonucleotide primers used to sequence pGRE are listed in S2 Table.

\section{Construction of vectors for cluster assembly}

pCLY9 vector was constructed using Gibson assembly method from PCR products generated in the following manner. DNA fragment encompassing pA15 replication origin was amplified with primers $15 \mathrm{aSOKf}$ and $15 \mathrm{aSOKr}$ using pACYC184 DNA template [15]. DNA fragment encompassing apramycin resistance gene, oriT, attP and phage VWB integrase gene was amplified using primers SOK15af and SOK15ar from pSOK804 DNA template. pCLY10 vector was constructed using Gibson assembly method from PCR products generated as follows. DNA fragment encompassing yeast centromere/replication origin CEN6/ARS4 and LEU2 marker was amplified with primers CEN_LEUf and CEN_LEUr using pRS415 DNA template (SnapGene, USA). DNA fragment encompassing 15a replication origin, apramycin resistance gene, oriT, attP and phage VWB integrase gene was amplified using primers CL9Lf and CL9Lr from the pCLY9 DNA template. pCLY11 vector was constructed using Gibson assembly method from PCR products generated as follows. DNA fragment encompassing yeast centromere/replication origin CEN6/ARS4, LEU2 marker, apramycin resistance gene, oriT, attP and phage VWB integrase gene was amplified with primers CLYbacf and CLYbacr using PCLY10 DNA template. DNA fragment encompassing $B A C$ replication origin and associated partition genes was amplified using primers BACclyf and BACclyr from the pCC1BAC DNA template (Epicentre, USA). Sequences of the oligonucleotide primers mentioned above are presented in S1 Table.

\section{Gene complementation cassettes}

To generate the expression vector pUWLgreM2, greM2 was amplified by PCR from $S$. sp. Acta 13-62 chromosomal DNA. Suitable restriction sites (XbaI and KpnI) were introduced upstream and downstream from the gene, using primers. Also forward primer was carrying $21 \mathrm{p}$ promoter. To obtain suitable shuttle vector, pUWLCre was treated with $K p n \mathrm{I} / \mathrm{XbaI}$ and $8 \mathrm{~kb}$-fragment was eluted from the agarose gel (done according to the manufacturer, Promega). $2.4 \mathrm{~kb}$ PCR-fragment was digested with $\mathrm{X} b a \mathrm{I}$ and $K p n \mathrm{I}$ and ligated into pUWL vector, to generate pUWLgreM2.

\section{gre gene cluster assembly using TAR}

Homologous sequences to the gre cluster were introduced into PCLY10 via PCR. Primers were designed to overlap $38 \mathrm{bp}$ of the $500 \mathrm{bp}$ long region upstream from the gre cluster (forward primer) and $38 \mathrm{bp}$ of the $130 \mathrm{bp}$ long region downstream from the cluster (reverse primer). Prior to the PCR pCLY10 was treated with HindIII, obtained PCR-product was treated with $D p n I$ for 3 hours. gre cluster was split into 3 parts: region 1, region 2 and region 3 (R1, R2 and $\mathrm{R} 3$ ), each size in range from 10 to $14 \mathrm{~kb}$. R1 and R3 were chosen for the first step of the cluster assembly. Primers for R1 were designed to overlap with 38bp pCLY10 (forward primer) and R3 (reverse primer); R3-primers had 38-bp long overlaps with R1 (forward primer) and pCLY10 (reverse primer). S. sp. Acta 13-62 chromosomal DNA was used as a template for PCR amplifications. Mixture of obtained PCR-products (R1, R3 and pCLY10) was transformed into Sac. cerevisiae BG4742 (LEU) cells in concentration $100 \mathrm{ng}$ each. After 4 days of incubation at $30^{\circ} \mathrm{C}$, transformants were picked from the plates, plasmid DNA was isolated and transformed into E. coli BG2005 cells. Verification of obtained constructs revealed pCLY10 carrying 
$\mathrm{R} 1$ and $\mathrm{R} 3$ regions (pCR1.R3). ScaI restriction site was introduced between R1 and R3 artificially using primers, thus giving possibility to introduce R2 into PCR1.R3. Due to the problems with PCR, R2 was split into two parts: R2.1 (5743 bp) and R2.2 (7586 bp), overlap between R2.1 and R1 was 110 bp, R2.2 and R3 49 bp, R2.1 and R2.2 41 bp. To amplify pCLY10, R1 and R3 MasterAmp ${ }^{\text {mw }}$ Extra-Long PCR Kit from Epicentre was used, to amplify R2.1 and R2.3 polymerase from the kit was substituted with Phusion High-Fidelity DNA Polymerase from Thermo Fisher Scientific. Mixture of R2.1, R2.2 PCR-products and pCR1.R3, treated with ScaI, was transformed into yeast cells. Transformants were picked from the plates after 4 days incubation at $30^{\circ} \mathrm{C}$, prior to plasmid DNA isolation, colony-PCR was done. Primers were specific to the DNA sequence that can be present only in a reassembled gene cluster construct. 22 positive clones were picked out of 95 after PCR, 4 clones were selected randomly and plasmid DNA was isolated. After verification by restriction mapping all four clones were positive for containing pR1.R3 reassembled with R2.1 and R2.2 (pGRE).

\section{Conditions for amplification of R1, R2.1, R2.2, R3 and pCLY10}

To amplify pCLY10, R1, R2.1, R2.2 and R3 Master-Amp ${ }^{\text {tw }}$ Extra-Long PCR Kit (Epicentre) was used: PreMix 4 for amplification R3 and R2.2, PreMix 8 for amplification R1 and R2.1. Phusion High-Fidelity DNA (Thermo Fisher Scientific) polymerase was used to amplify R2.1 and R2.2, and Master-Amp ${ }^{\text {tw }}$ Extra-Long Polymerase Mix (Epicentre) for R1 and R3 amplification. PCR conditions for R1, R2 and R3 amplification are listed in S3 Table.

\section{Transformation of yeast}

Yeast transformation was done as described before [16].

\section{Isolation of plasmid DNA from yeast}

Plasmid DNA was isolated from the yeast cells using Wizard Plus SV Miniprep kit from Promega. 37,5 Units of Longlife Zymolyase (G-Biosciences, USA) were added to P1 buffer, samples were incubated at $37^{\circ} \mathrm{C}$ for $30-60 \mathrm{~min}$. Further steps were done according to the manufacturer.

\section{Purification of compounds}

S. albus pGRE was cultivated in DNPM medium in shaking flasks, total volume $5 \mathrm{~L}$ at $30^{\circ} \mathrm{C}$, $200 \mathrm{rpm}$ for 5 days. Mixture of culture broth and biomass was extracted with $5 \mathrm{~L}$ of ethylacetate (EtAc) and led to $145 \mathrm{mg}$ of crude extract. The extract was purified by HPLC (HTec C18 column, $250 \times 10 \mathrm{~mm}, 5 \mu \mathrm{m}, \mathrm{A}=\mathrm{H} 2 \mathrm{O}+0.1 \% \mathrm{FA}, \mathrm{B}=\mathrm{ACN}+0.1 \% \mathrm{FA}$ ) with gradient starting from $5 \% \mathrm{~B}$ to $95 \% \mathrm{~B}$ in $28.2 \mathrm{~min}$. Flow $5.8 \mathrm{ml} / \mathrm{min}$, injection volume $40 \mu \mathrm{l}$ of an $\mathrm{MeOH}$ extract ( $c=5.3 \mathrm{mg} / \mathrm{ml}$ ), detection wavelength $\lambda=420 \mathrm{~nm}$.

\section{Production analysis}

For production analysis $3 \mathrm{ml}$ of 24 -h old pre-culture of $S$. albus pGRE was inoculated into 50 $\mathrm{ml}$ of DNPM media and grown for 4 days at $30^{\circ} \mathrm{C}$ with agitation at $200 \mathrm{rpms}$. The culture broth was extracted with ethylacetate, samples were evaporated, dissolved in $500 \mu \mathrm{l}$ of methanol and subjected to LC-MS analysis.

Standard measurements were performed on a Dionex Ultimate 3000 RSLC system using a BEH C18, $100 \times 2.1 \mathrm{~mm}, 1.7 \mu \mathrm{m} \mathrm{d}_{\mathrm{p}}$ column (Waters, Germany). Separation was achieved by a linear gradient from (A) $\mathrm{H}_{2} \mathrm{O}+0.1 \% \mathrm{FA}$ to (B) $\mathrm{ACN}+0.1 \% \mathrm{FA}$ at a flow rate of $600 \mu \mathrm{L} / \mathrm{min}$ at $45^{\circ} \mathrm{C}$. The gradient was initiated by a $0.5 \mathrm{~min}$ isocratic step at $5 \% \mathrm{~B}$, followed by an increase to $95 \%$ B in 18 min to end up with a 2 min step at $95 \%$ B before re-equilibration under the initial 
conditions. UV spectra were recorded by a DAD in the range from 200 to $600 \mathrm{~nm}$. MS data was acquired with an Amazon Speed 3D ion trap mass spectrometer (Bruker Daltonics, Germany) using the Apollo ESI source. Mass spectra were acquired in centroid mode ranging from 150 to $1500 \mathrm{~m} / \mathrm{z}$.

High-resolution measurements were performed on a Dionex Ultimate 3000 RSLC system using a BEH C18, $100 \times 2.1 \mathrm{~mm}, 1.7 \mu \mathrm{m} \mathrm{d}_{\mathrm{p}}$ column (Waters, Germany). Separation of a $1 \mu \mathrm{l}$ sample was achieved by a linear gradient from (A) $\mathrm{H}_{2} \mathrm{O}+0.1 \% \mathrm{FA}$ to (B) $\mathrm{ACN}+0.1 \% \mathrm{FA}$ at a flow rate of $600 \mu \mathrm{L} / \mathrm{min}$ and $45^{\circ} \mathrm{C}$. The gradient was initiated by a $0.5 \mathrm{~min}$ isocratic step at $5 \%$ B, followed by an increase to $95 \%$ B in 18 min to end up with a 2 min step at $95 \%$ B before reequilibration under the initial conditions. UV spectra were recorded by a DAD in the range from 200 to $600 \mathrm{~nm}$. The LC flow was split to $75 \mu \mathrm{L} / \mathrm{min}$ before entering the maXis $4 \mathrm{G} \mathrm{hr}-\mathrm{ToF}$ mass spectrometer (Bruker Daltonics, Germany) using the Apollo ESI source. Mass spectra were acquired in centroid mode ranging from $150-2500 \mathrm{~m} / \mathrm{z}$ at a $2 \mathrm{~Hz}$ scan rate.

\section{Results}

\section{Grecocycline biosynthetic gene cluster identification and bioinformatic analysis}

The Streptomyces sp. Acta1362 draft genome contains 8,710,318 base pairs with an average GC content of $71 \%$ and includes 8,026 open reading frames. Using antiSMASH [17] we have predicted 41 potential biosynthetic gene clusters, among them two encoding type II PKS systems. As grecocyclines contain sugar moieties [18] (Fig 1), the presence of genes encoding glycosyltransferases and deoxysugar biosynthesis enzymes are expected to be present within the biosynthetic gene cluster. Indeed, three genes for glycosyltransferases were identified in one of the type II PKS gene clusters, along with the genes required for deoxysugars biosynthesis, genes encoding post-PKS tailoring enzymes, regulatory and transporter genes. Altogether they comprise the putative grecocycline biosynthetic gene cluster (gre cluster) that encompassing 32 predicted open reading frames (ORFs) (Fig 2, Table 1).

Several genes involved in the angucycline formation and maturation are present in the cluster: 1) the type II PKS gene set is represented by greA 1 , greA2 and greA 3 encoding alpha and beta ketosynthases (KS $\alpha$ and $\mathrm{KS} \beta$ ) and acyl carrier protein (ACP), respectively; 2) two cyclase encoding genes-greA4 and gre $45 ; 3)$ three ketoreductase encoding genes-greA6, greV and greO; 4) four oxygenase genes-greM2, greE, greL and greD; 5) one gene, greA7, encoding 4'phosphopantetheinyl transferase presumably responsible for generation of holo-ACP; and 6) the gene encoding a decarboxylase, greN. Interestingly, greD is the only gene transcribed from the antisense strand. An additional gene encoding enzyme presumably acting on the angucyclic core of the grecocyclines is greTh. The deduced amino acid sequence of GreTh is highly similar to thioesterases and may be involved in formation of the thiol group in grecocycline B.

Two different deoxysugars are attached to the angucycline core: L-rhodinose and L-tolyposamine. Eleven of the thirty-two genes in the gre cluster encode enzymes that are presumably involved in the biosynthesis and transfer of sugars to the polyketide. The genes gre $G$, greH, greS, greT, greQ, greZ1 and greZ3 encode enzymes that are predicted to be involved in the formation of NDP-rhodinose from D-glucose-1-phosphate. Additionally, greJ encodes NDPhexose-4-aminotransferase that probably transfers amino group to the hexose to form Ltolyposamine.

Grecocyclines contain three sugar moieties, and a corresponding number of glycosyltransferase encoding genes was identified in the gre cluster-GreGT1, GreGT2 and GreGT4. greGT2 encodes a protein that is homologous to SaqGT5 and UrdGT2 $[19,20]$ and may be involved in the attachment of L-rhodinose at the C-9 position of the aglycon, similar to 
A

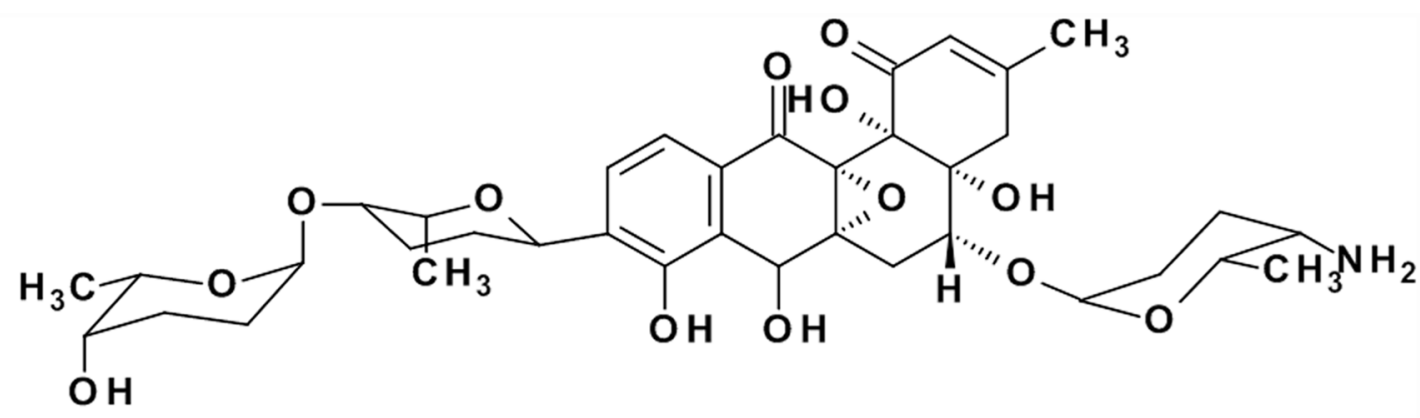

B

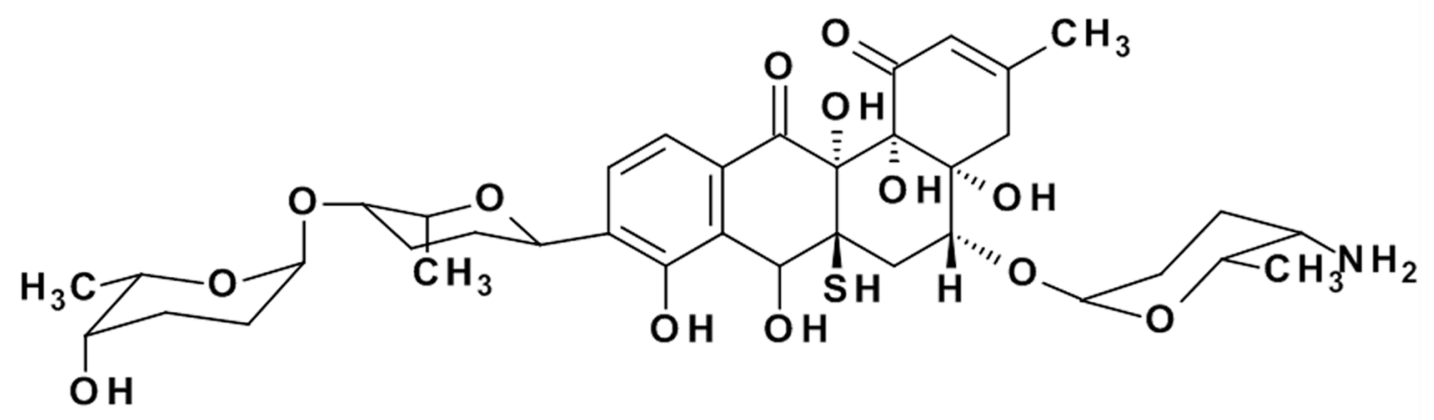

C

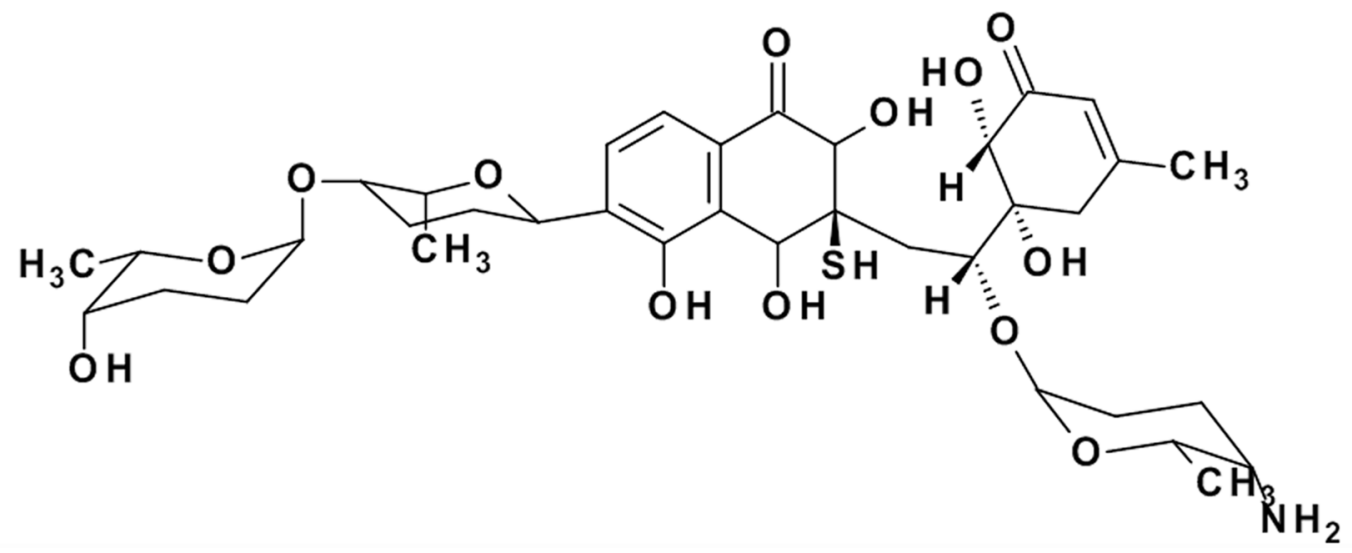

Fig 1. Structures of grecocylines A (A), B (B) and C (C).

doi:10.1371/journal.pone.0158682.g001

urdamycins and saquayamycins. Probably, GreGT1 is responsible for the introduction of a second L-rhodinose unit, as it is highly similar to SaqGT3, SaqGT4, LanGT1 which are responsible for the extension of an oligosaccharide chain in angucyclines [19-21]. To our knowledge, grecocyclines are the first angucyclines that carry the sugar moiety at C-5 position of the

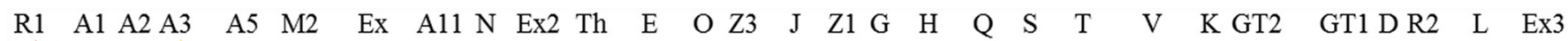

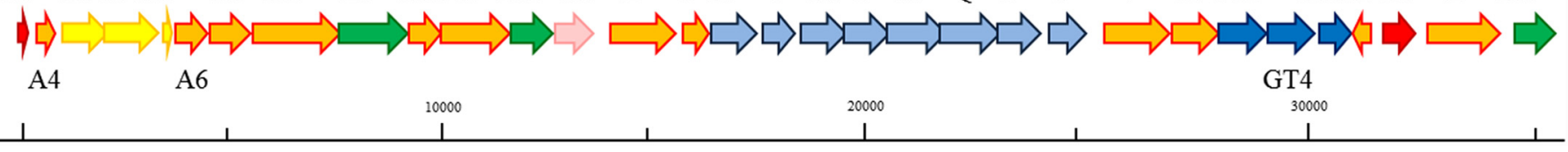

Fig 2. Grecocycline biosynthetic gene cluster (gre) from S. sp. Acta 13-62. In yellow are labeled genes encoding type II PKS, orange-genes involved in angucycline formation, blue-genes involved in biosynthesis of rhodinose and $\alpha$-tolyposamine, dark blue-genes encoding glycosyltransferases, pink—gene encoding putative thioesterase, green—efflux, red—regulatory genes. Dashed arrow indicates formation of shunt product grecocycline $\mathrm{C}$.

doi:10.1371/journal.pone.0158682.g002 
Table 1. Deduced function of ORFs in the grecocycline biosynthetic gene cluster.

\begin{tabular}{|c|c|c|c|c|c|}
\hline Polypeptide & aa & Similar protein & Acc. number & Identity & Proposed function \\
\hline GreR1 & 216 & PgaR1; Streptomyces sp. PGA64 & AHW57766.1 & $68 \%$ & transcriptional regulator \\
\hline GreA4 & 110 & $\begin{array}{l}\text { LndF; Streptomyces globisporusJadl; Streptomyces } \\
\text { venezuelae }\end{array}$ & AAU04837.1AAO65345.1 & $\begin{array}{l}82 \% \\
81 \%\end{array}$ & polyketide cyclase \\
\hline GreA1 & 354 & PgaA; Streptomyces sp. PGA64 & AAK57525.1 & $85 \%$ & ketosynthase alfa \\
\hline GreA2 & 405 & PgaB; Streptomyces sp. PGA64 & AAK57526.1 & $73 \%$ & ketosynthase beta \\
\hline GreA3 & 92 & PgaC; Streptomyces sp. PGA64 & AAK57527.1 & $72 \%$ & acyl carrier protein \\
\hline GreA6 & 262 & PgaD; Streptomyces sp. PGA64 & AAK57528.1 & $87 \%$ & ketoreductase \\
\hline GreA5 & 315 & $\begin{array}{l}\text { UrdL; Streptomyces fradiaePgaL; Streptomyces sp. } \\
\text { PGA64 }\end{array}$ & AAF00205.1AAK57529.1 & $\begin{array}{l}79 \% \\
74 \%\end{array}$ & aromatase \\
\hline GreM2 & 794 & PgaM; Streptomyces sp. PGA64 & AAK57530.1 & $67 \%$ & two-domain mono-oxygenase \\
\hline GreEx & 503 & PgaJ; Streptomyces sp. PGA64 & AAK57531.1 & $53 \%$ & transporter \\
\hline GreA11 & 236 & OvmF; Streptomyces antibioticus & CAG14972.1 & $63 \%$ & $\begin{array}{l}\text { 4'-phosphopantetheinyl } \\
\text { transferase }\end{array}$ \\
\hline GreN & 515 & Pgal; Streptomyces sp. PGA64 & AAK57534.1 & $84 \%$ & $\begin{array}{l}\text { acyl-CoA carboxylase, beta- } \\
\text { subunit }\end{array}$ \\
\hline GreEx2 & 391 & uncultured soil bacterium V167 & ACX83629.1 & $59 \%$ & $\begin{array}{l}\text { putative major facilitator } \\
\text { transporter }\end{array}$ \\
\hline GreTH & 305 & Streptomyces roseoverticillatus & WP_030366371.1 & $63 \%$ & thioesterase \\
\hline GreE & 498 & PgaE; Streptomyces sp. PGA64 & AAK57522.1 & $97 \%$ & monooxygenase \\
\hline GreO & 199 & UrdO; Streptomyces fradiae & AAF00220.1 & $62 \%$ & reductase \\
\hline GreZ3 & 341 & PgaZ3; Streptomyces sp. PGA64 & AHW57779.1 & $45 \%$ & TDP-hexose-4-ketoreductase \\
\hline GreJ & 384 & PgaC1; Streptomyces sp. PGA64 & AHW57776.1 & $80 \%$ & TDP-hexose-4-aminotransferase \\
\hline GreZ1 & 200 & PgaZ1; Streptomyces sp. PGA64 & AHW57777.1 & $74 \%$ & TDP-hexose-3,5-epimerase \\
\hline GreG & 356 & PgaG; Streptomyces sp. PGA64 & AHW57786.1 & $75 \%$ & TDP-hexose synthetase \\
\hline GreH & 337 & PgaH1; Streptomyces sp. PGA64 & AHW57787.1 & $83 \%$ & TDP-hexose-4,6-dehydratase \\
\hline GreQ & 435 & PgaQ; Streptomyces sp. PGA64 & AHW57788.1 & $86 \%$ & TDP-hexose-3,4-dehydratase \\
\hline Gres & 465 & PgaS; Streptomyces sp. PGA64 & AHW57789.1 & $71 \%$ & TDP-hexose-2,3-dehydratase \\
\hline GreT & 328 & PgaT; Streptomyces sp. PGA64 & AHW57790.1 & $66 \%$ & TDP-hexose-3-ketoreductase \\
\hline GreV & 254 & LanV; Streptomyces cyanogenus & AAD13552.1 & $62 \%$ & Reductase homolog \\
\hline GreK & 497 & SaqE; Micromonospora sp. Tu 6368 & ACP19351.1 & $68 \%$ & putative oxygenase \\
\hline GreGT2 & 379 & SaqGT5; Micromonospora sp. Tu 6368 & ACP19370.1 & $59 \%$ & glycosyltransferase \\
\hline GreGT4 & 425 & Lcz36; Streptomyces sanglieri & ABX71153.1 & $54 \%$ & glycosyltransferase \\
\hline GreGT1 & 392 & SaqGT3; Micromonospora sp. Tu 6368 & ACP19364.1 & $59 \%$ & glycosyltransferase \\
\hline GreD & 217 & FrnE; Streptomyces roseofulvus & AAC18100.1 & $56 \%$ & DSBA oxidoreductase \\
\hline GreR2 & 118 & Streptomyces sp. CNH287 & WP_027750658.1 & $59 \%$ & $\begin{array}{l}\text { HxIR family transcriptional } \\
\text { regulator }\end{array}$ \\
\hline GreL & 227 & Actinoplanes missouriensis & WP_014442785.1 & $40 \%$ & putative monooxygenase \\
\hline GreEx3 & 542 & Streptomyces sp. W007 & WP_007448654.1 & $95 \%$ & MFS transporter \\
\hline
\end{tabular}

doi:10.1371/journal.pone.0158682.t001

angucyclic core. Furthermore, $\alpha$-tolyposamine is a very rare deoxysugar in natural products, so far found only in compound BU-4514N from Microtetraspora sp. [22]. It seems plausible that GreGT4 is transferring this aminosugar to the $\mathrm{C}-5$ position of grecocyclines. The deduced amino acid sequence of GreGT4 shares 54\% identity with Lcz3 from the lactanomycin gene cluster and 50\% identity with UrdGT1a involved in urdamycin biosynthesis[23, 24]. As mentioned above, greL encodes monooxygenase that does not have a predicted function, and might be a potential candidate for hydroxylation of the aglycon at C-5 prior to the sugar attachment (Fig 3). 


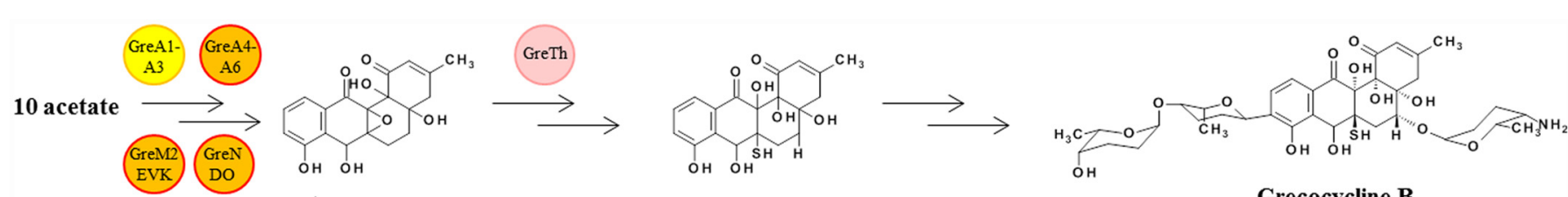

Grecocycline B
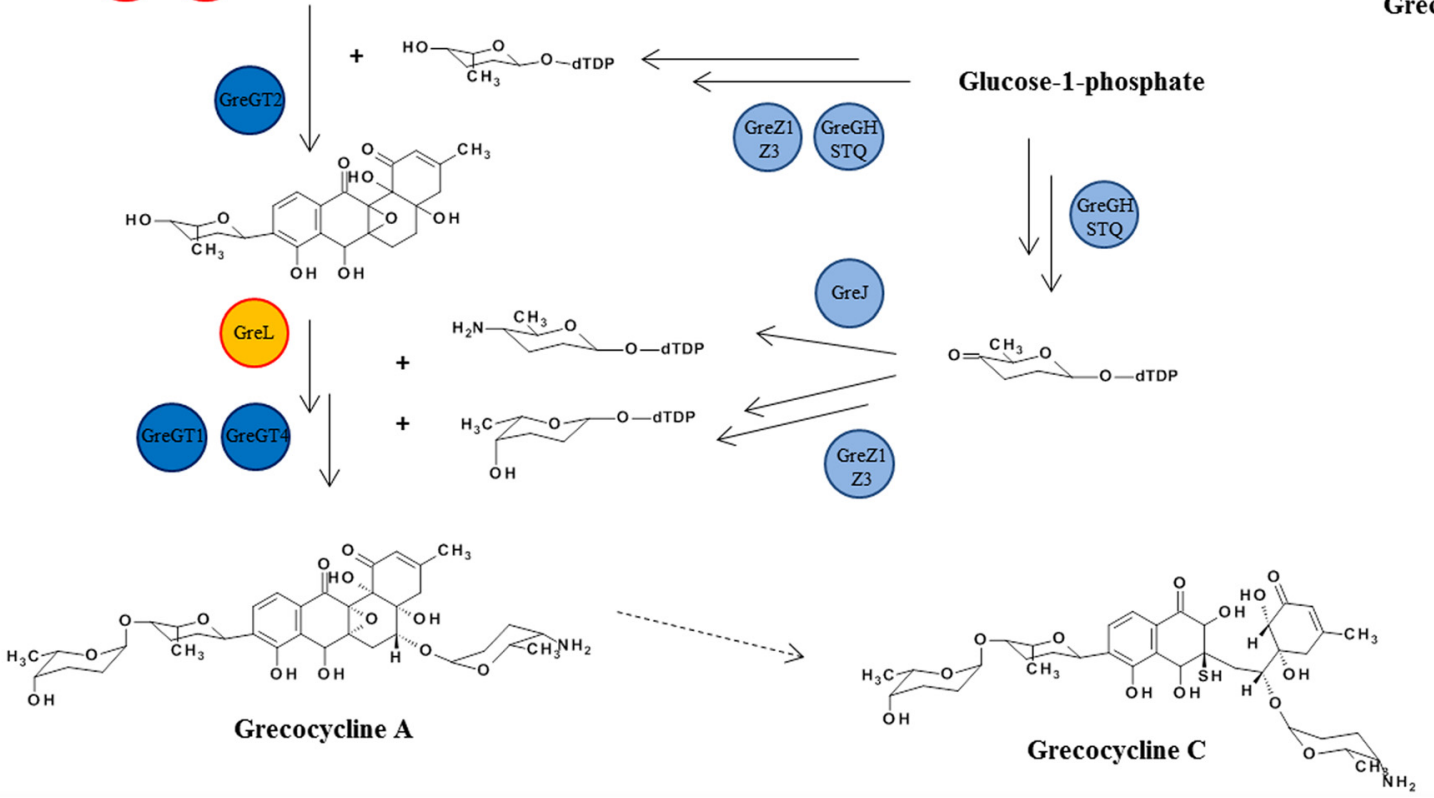

Fig 3. Proposed biosynthesis of grecocyclines. In circles are indicated enzymes putatively involved in particular biosynthetic steps.

doi:10.1371/journal.pone.0158682.g003

Two regulatory (greR1, greR2) and three transporter genes (greEx, greEx2 and greEx3) were identified in the gre cluster. greR1 is located at the 5 ' end of the gene cluster, and encodes a protein with the similarity to transcriptional regulators of the OmpR family [25]. Deduced amino acid sequence of GreR1 is very similar to JadR1 and LndI. Disruption of $\ln d I$ caused complete loss of landomycin E production in S. globisporus, while its overexpression led to an increase in the antibiotic production $[26,27]$. LndI is an autoregulator as it can bind to its own promoter region as well as to the promoters of the lnd structural genes [28]. Presumably, GreR1 plays the same role in the grecocycline biosynthesis. GreR2 is homologous to the HxlR family of transcriptional regulators. GreEx, GreEx2 and GreEx3 are similar to MFS transporters and probably are exporting grecocyclines out of the cell.

All the attempts to generate the deletion mutants in S. sp. Acta 13-62 in order to confirm the identity of the gre cluster failed, and therefore we decided to assemble the gene cluster for heterologous expression.

\section{Construction of the TAR assembly vectors}

To construct vectors capable of harboring large DNA fragments, a bifunctional plasmid pCLY9 (Fig 4) representing a hybrid between pACYC184 [29] and pSOK804 [30] was assembled using Gibson ligation method [31] (see Materials and Methods for details). In particular, ColE1 replicon in pSOK804 was replaced with that of p15A, yielding a conjugative shuttle vector PCLY9 that could be transferred to Streptomyces via intergeneric conjugation and site-specifically integrated into the chromosome. Next, pCLY9 was used in an attempt to assemble several gene clusters ranging in size from $30 \mathrm{~kb}$ to $50 \mathrm{~kb}$ using Gibson ligation method (data not shown). However, none of these attempts were successful, most likely due to formation of 


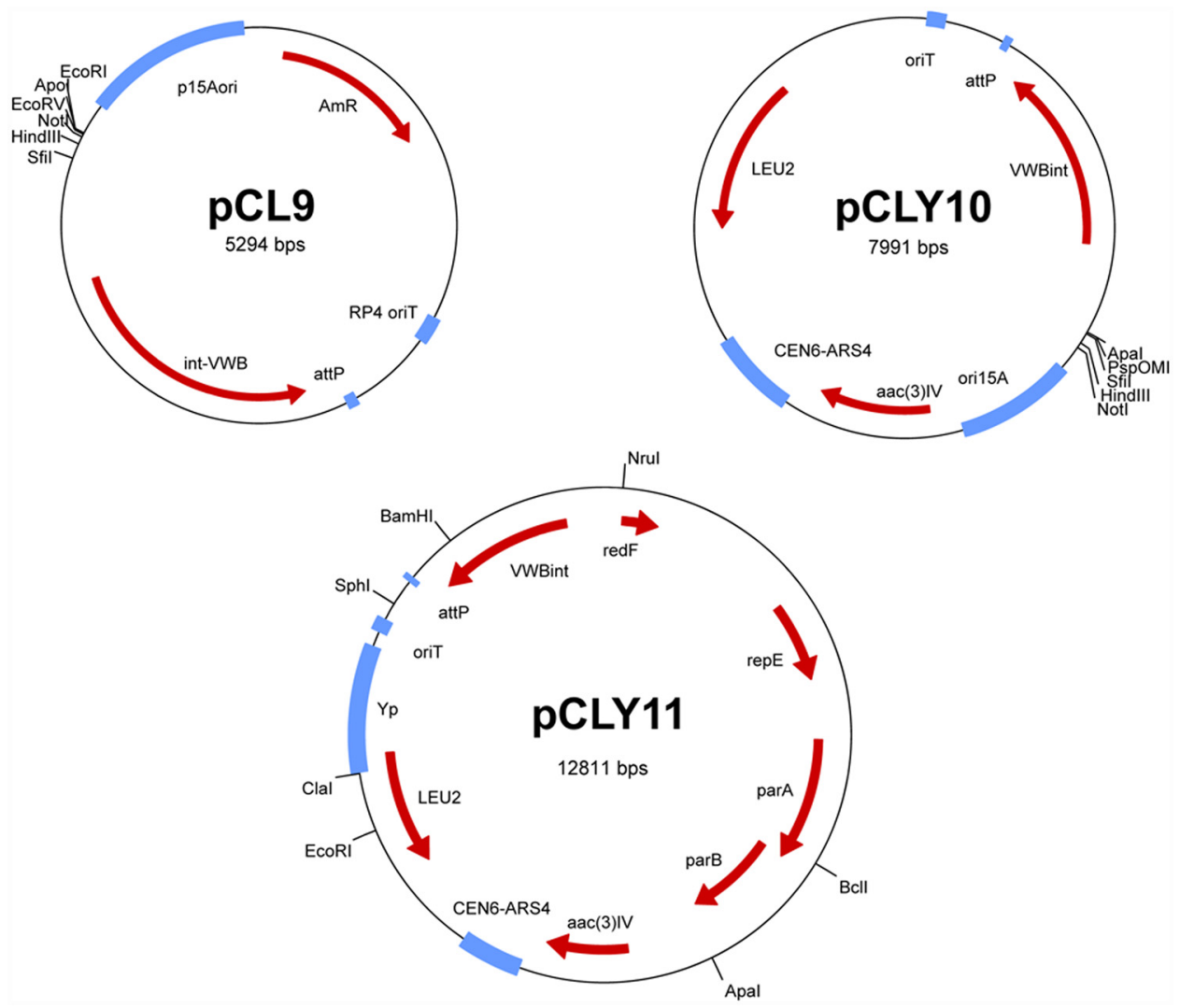

Fig 4. Physical maps of the vectors constructed in this study (see text for details).

doi:10.1371/journal.pone.0158682.g004

secondary structures by single stranded GC-rich DNA generated during exonuclease "chewback" which would prevent proper alignment of complimentary strands during assembly.

To circumvent this problem, two vectors carrying elements allowing propagation in yeast were constructed. pCLY10 (Fig 4) was generated via insertion of yeast LEU2 marker gene and CEN-ARS4 centromere/replication origin elements from plasmid pRS415 [32] into pCLY9 via Gibson assembly (see Materials and Methods). pCLY11 was derived from pCLY10 by replacing the p15a replication origin with part of the pCC1BAC vector harboring F-factor replicon and having a copy control function. Both pCLY10 and PCLY11 were shown to propagate stably in E. coli and yeast Sac. cerevisiae, and to be efficiently transferred to S. noursei, S. venezuelae and S. albus. pCLY10 was chosen for grecocyline biosynthetic gene cluster assembly.

\section{Grecocylcine gene cluster assembly in yeast}

To express the gene cluster in the heterologous host, we targeted appropriate DNA region for TAR cloning (Fig 5). Previous reports showed that short 40- to 70-bp DNA-specific targeting sequences were enough for successful TAR cloning [33]. The grecocycline biosynthetic gene cluster was split into three regions, R1, R2 (R2.1 and R2.2) and R3, overlapping with each other and with the shuttle vector (pCLY10) by $38 \mathrm{bp}$. The capture arms to the gre cluster were introduced into pCLY10 via PCR to generate pCLY10ol. Primers were designed to overlap $38 \mathrm{bp}$ of the $500 \mathrm{bp}$ long region upstream from the gre cluster (forward primer) and $38 \mathrm{bp}$ of the $130 \mathrm{bp}$ long region downstream from the cluster (reverse primer). Assembly of the gre cluster was done in two steps: 1) capture of R1 and R3 on the shuttle vector to give pR1R3;2) capture of 


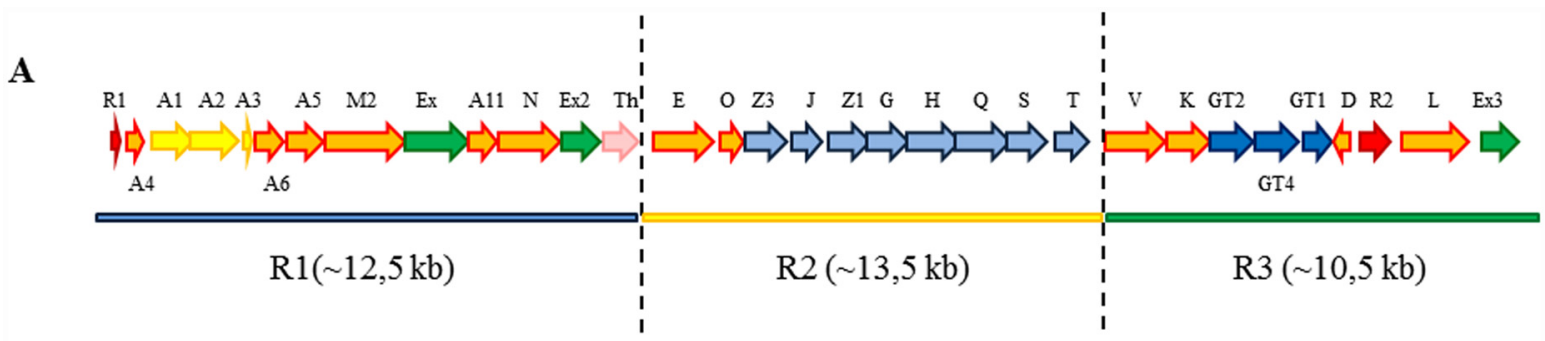

R1

B

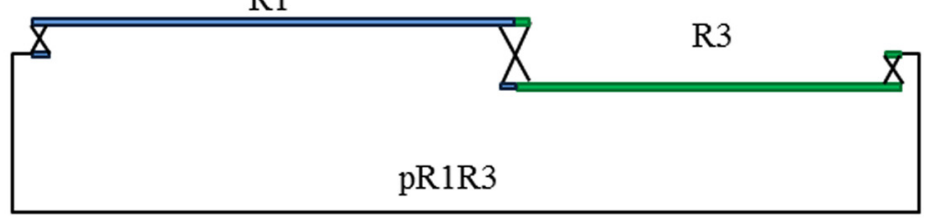

$\mathrm{R} 2.1$

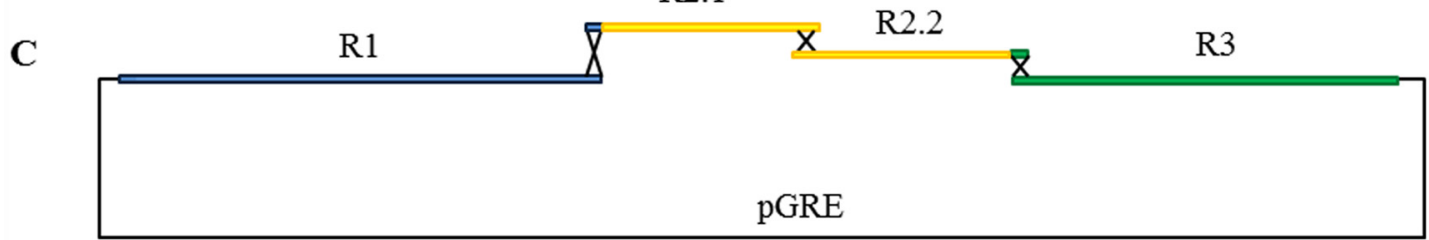

Fig 5. Strategy for assembling the grecocycline biosynthetic gene cluster using TAR. A-gre cluster divided on R1, R2 and R3; $B$-assembly of $p R 1 . R 3 ; C$-assembly of pGRE.

doi:10.1371/journal.pone.0158682.g005

R2 on pR1R3 to yield pGRE. R1, R2 and R3 were amplified in PCR reaction with the primers carrying homologous arms to the adjacent DNA regions. After transformation of Sac. cerevisiae BY4742 cells with the mixture of obtained PCR-products (R1, R3 and pCLY10ol), positive clones were identified by PCR and confirmed by restriction mapping to yield $\mathrm{pR} 1 \mathrm{R} 3$ construct. Next, linearized pR1R3 and R2 (R2.1 + R2.2) were transformed into yeast cells, yielding an assembly of pGRE-a construct carrying the entire gre biosynthetic gene cluster. On this stage the efficiency of TAR was approximately 23\% (see Methods and Materials section for further information). The 44-kb pGRE construct was stably maintained in E. coli.

\section{Heterologous expression of the assembled gre gene cluster}

For the heterologous production, we chose S. albus J1074, a model streptomycete commonly used as a host for heterologous expression of various biosynthetic gene clusters, and for which genome sequence has recently become available [34]. pGRE was introduced into the genome of S. albus J1074 by conjugative transfer from E. coli, and the resulting recombinant strain was analyzed for production of grecocyclines (see Materials and Methods). S. albus strain carrying pGRE (S. albus pGRE) was found to produce a series of angucyclines, as revealed by the ESI-MS analysis (Fig 6, S1 and S2 Figs). 


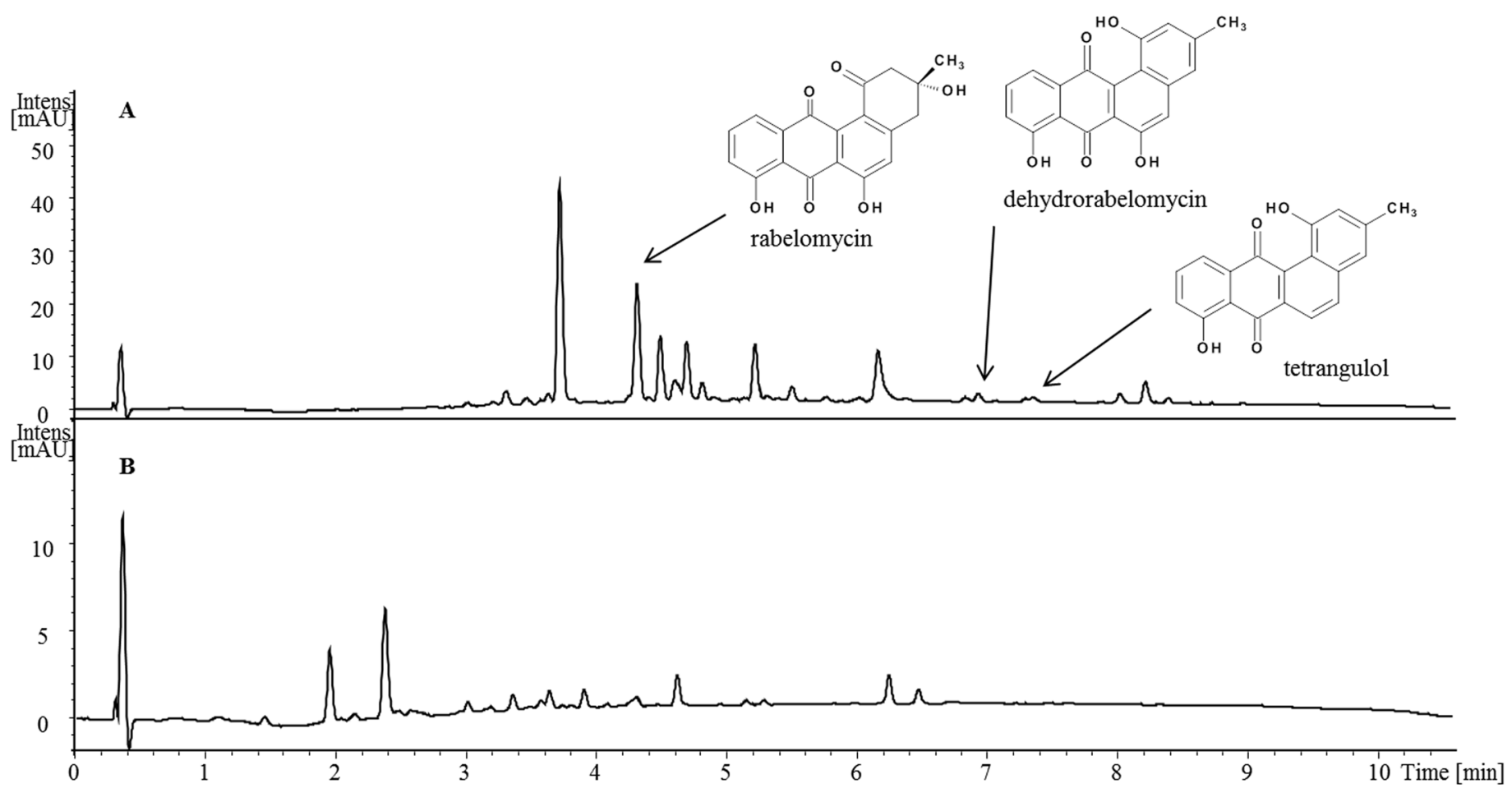

Fig 6. Chromatogramof the HPLC-ESI/MS analysis of crude extract from S. albus pGRE (A) and S. albus J1074 (B). Arrows indicate ions corresponding to rabelomycin, dehydrorabelomycin and tetrangulol. Wavelength $420 \mathrm{~nm}$.

doi:10.1371/journal.pone.0158682.g006

To determine the chemical structures of produced compounds, S. albus pGRE was cultivated in $5 \mathrm{~L}$-scale to yield $\sim 130 \mathrm{mg}$ of crude extract solids, from which ten fractions were purified and subsequently analyzed by LC-MS. Three compounds from fractions N4, N9 and N10 were assigned to known angucycline intermediates or shunt products, based on the UV/Vis spectra and the accurate mass. The compound from fraction $\mathrm{N} 4$ was identified as rabelomycin $(\mathrm{m} / \mathrm{z}=338.07863)$, fractions $\mathrm{N} 9$ and $\mathrm{N} 10$ were shown to contain dehydrorabelomycin $(\mathrm{m} /$ $\mathrm{z}=320.06741)$ and tetrangulol $(\mathrm{m} / \mathrm{z}=304.07257)$, respectively. No glycosylated products have been detected after the heterologous expression of assembled gre cluster in S. albus. Although no grecocyclines were detected in the crude extracts via LC-MS analysis, it was obvious that the cloned biosynthetic gene cluster is responsible for grecocycline precursor's biosynthesis, since several known angucyclines were observed. To identify the reason why after the heterologous expression of cloned gre gene cluster no grecocyclines were produced we have sequenced the pGRE plasmid using primer walking, covering approximately $97,1 \%$ of the construct. Analysis of the sequenced data revealed twenty six nucleotide substitutions, presumably introduced during PCR. All the identified mutations are listed in Table 2 and discussed in the Discussion section.

Eight nucleotide substitutions were identified in the DNA region encoding GreM2. Inactivation of greM2 homologs in urdamycin and landomycin biosynthetic pathways led to accumulation of rabelomycin, tetrangulol and other shunt products $[35,36]$, preventing subsequent conversion of aglycon into the glycosylated natural product.

To complement mutated region encoding greM2, a native greM2 was placed under the control of the strong synthetic $21 \mathrm{p}$ promoter and cloned into pUWL vector. Introduction of this construct into the S. albus pGRE strain did not change the spectrum of the compounds 
Table 2. List of mutations introduced into the gre genes during amplification*.

\begin{tabular}{l|l|l}
\hline Protein & Mutation & Proposed function \\
\hline GreA5 & A217T & aromatase \\
\hline GreM & A2T; R339C; G407C; P665L; R734C; E747G & bifunctional oxygynase-reductase \\
\hline GreN & I353V & carboxylase \\
\hline GreK & V79V**; K101K**; L387P; & putrative oxygenase \\
\hline GreGT4 & W22R & glycosyltransferase \\
\hline GreGT1 & A291A** & glycosyltransferase \\
\hline GreD & E147V & DSBA oxidoreductase \\
\hline GreL & P104T; R106Q & putative monooxygenase \\
\hline GreEx3 & I322F; A500V & MFS transporter \\
\hline
\end{tabular}

* -mutations in the intergenic regions are not included

** -nucleotide substitution do not influence amino acid sequence

doi:10.1371/journal.pone.0158682.t002

observed after the expression of assembled gre cluster alone. This result may reflect an unbalanced expression of greM2 and the rest of the gre cluster from different plasmids.

\section{Discussion}

For many decades actinomycetes have been the source of numerous pharmaceutically useful compounds which were developed into antibiotics, immunosuppressive, antiproliferative and antiparasitic drugs [37]. The fast progress in DNA sequencing technologies applied to genome sequencing revealed the wealth of natural product biosynthetic gene clusters in the genomes of actinomycetes, most of which remain cryptic [38]. One approach to access chemical diversity encoded by the cryptic/silent biosynthetic gene clusters is heterologous expression, while cloning of large gene clusters still represent a challenge. Therefore, technics for large DNA fragments cloning are of great interest.

In this study, we used TAR method to assemble and heterologously express grecocycline biosynthetic gene cluster. The entire $36-\mathrm{kb}$ gene cluster was successfully captured on the shuttle vector carrying short (38-bp) homologous shoulders. We accomplished cluster assembly in two steps. The advantage of step-by-step strategy is very fast and effortless acquisition of all parts in large quantities, which facilitates their joining during TAR-assisted assembly. The only limiting step may be finding of the appropriate conditions for DNA amplification via PCR. The composition of transformation mixture used in TAR is thus free from excessive and nonrelated DNA generated when a digested genomic DNA mixture is used. The latter strategy may significantly reduce the recombination frequency and make assembly problematic. Hence, TAR-assisted cloning with only essential fragments may increase frequency of the correct assembly in a fold range. Another advantage of the PCR-based TAR assembly is introduction of homologous shoulders directly at the ends of the targeted DNA sequence. As was shown before, homologous recombination is much more efficient between TAR vector and the DNA sequence located closer to the ends compared to internally imbedded [39]. Application of a CRISPR/Cas9 system to introduce double-strand breaks close to the ends of the desired genomic fragment resulted in a dramatic increase in the fraction of gene-positive colonies [13]. The numbers of positive yeast clones from this study $(23 \%)$ are comparable with efficiency of CRISPR/Cas9-mediated TAR cloning (32\%). However, the disadvantage of the PCR-based part generation is certainly high risk of mutations, especially when long fragments are synthesized by DNA polymerases from GC-rich DNA. Therefore, the result of a seemingly correct assembly (e.g. verified only via restriction endonuclease digestion patterns) is to a large extent 
unpredictable, since absence of expected product can be either due to mutations introduced by PCR, or other reasons. On the other hand, randomly introduced mutations may provide an advantage in terms of generation of new analogues. Such method can be applied to any cloned gene cluster for which heterologous expression have been verified. Overlapping parts of such cluster can be amplified by error-prone PCR, re-assembled using TAR, and heterologous hosts carrying mutagenized clusters screened for new analogues or enhanced production of target compound.

The potential usefulness of this approach is in part supported by the expression of re-assembled gre gene cluster in S. albus. Undoubtedly, the angucycline compounds, which we have isolated, are produced after the expression of the gre biosynthetic gene cluster from pGRE, since the host S. albus lacks type II PKS-encoding genes. Although no grecocycline have been detected after heterologous expression of the gre gene cluster, the recombinant strain produced rabelomycin, dehydrorabelomycin and tetrangulol, known intermediates and shunt products formed during biosynthesis of angucycline polyketides [36, 40-42]. These data are also in agreement with the mutations detected in the greM2 gene on pGRE. The deduced amino acid sequence of GreM2 shows significant similarity to the bifunctional oxygenase-reductases from the landomycin (LndM2, LanM2), gaudimycin (PgaM), and jadomycin (JadF, partially) biosynthetic pathways. LanM2 and PgaM belong to the family of short-chain alcohol dehydrogenases/reductases (SDRs) and are translated as the two-domain flavoprotein oxygenase fusion with a separate C-terminal SDR $[35,43,44]$. LanM2 was shown to catalyze a thioesterase-like decarboxylative 2,3-dehydration of the ACP-tethered nascent angucycline generated by "minimal" PKS [44]. This reaction yields prejadomycin, which is recognized by further enzymes involved in the landomycins biosynthesis. The same reaction was proven in the in vitro studies for JadF during one-pot defucogilvocarcin enzymatic biosynthesis, where its removal led to accumulation of rabelomycin [45]. Thus, accumulation of rabelomycin by recombinant $S$. albus harboring pGRE may be due to the lack of GreM2 N-terminal oxidative activity. On the other hand, conversion of UWM6, the first intermediate in the angucycline's biosynthesis, into rabelomycin was observed after incubation with LanE [44]. LanE homolog in grecocycline biosynthetic gene cluster is represented by GreE (74\% identity with LanE and 76\% identity with $\mathrm{PgaE}$ ). Consequently, rabelomycin may originate from UWM6, which is recognized as a substrate by GreE. Only the oxygenase domain of GreM2 is required to release angucyclic intermediate tethered to ACP. One amino acid substitution (A2T) was identified in the sequence of greM2 encoding $\mathrm{N}$-terminal domain. This mutation occurred in the first amino acid after methionine and may not change enzymatic activity and folding of the GreM2 oxygenase domain. However, three amino acid substitutions were identified in the reductase domain encoding sequence of greM2, which would likely impair its catalytic activity. Therefore, we presume that mutated GreM2 may keep oxygenase activity and perform 2,3-dehydration of the ACP-tethered angucycline to give prejadomycin, which is recognized by GreE and (a) converted to dehydrorabelomycin or (b) in cooperation with GreV, generate tetrangulol.

Complementation of mutated greM2 gene with the native gene copy had no impact on the production profile of S. albus. As was shown before, the balanced expression of genes encoding enzymes from the biosynthetic pathways is crucial for production levels [46, 47]. In this study we used a high-copy number plasmid and a strong synthetic promoter to enforce greM2 transcription, while the whole gre cluster was present only in one copy per genome under the control of native promoters. Imbalance between copy-number and strength of promoters could explain why complementation did not trigger grecocycline production. Secondly, another three genes (greD, greL and greGT4) encoding enzymes involved in further biosynthetic steps had been mutated. Co-expression of these genes together with greM2, perhaps under the different conditions, might be needed for production of the glycosylated compounds. Another, and 
perhaps more plausible explanation, is that GreM2 actually functions at later step of the grecocycline biosynthesis, and cannot utilize precursors accumulating due to the lack of modifications by any or all GreD, GreL and GreGT4 enzymes.

Other nucleotide substitutions were located in the genes encoding GreA5, GreN, GreK, GreGT1, GreGT4, GreD, GreL and GreEx3 (Table 2). On two occasions mutations did not influence amino acid sequences (in GreGT1 and GreK). Clearly, the mutation in greA5 did not have impact on the protein function, otherwise aromatic polyketides would not be formed. Most probably, mutation in GreN (I353V) also did not affect the enzyme activity significantly. GreN is highly similar ( 80\%) to different acetyl-CoA carboxyltransferases, and orthologs of this enzyme have been identified in many gene clusters of secondary metabolites [20,48,49]. For example, acyl-CoA carboxylase JadJ, from the jadomycin biosynthetic pathway, is supplying malonyl-CoA for the polyketide biosynthesis, and its inactivation severely reduced jadomycin B production [48]. Isoleucine and valine are highly similar amino acids and their swapping may not influence folding and activity of the enzyme. This is supported by significant yields of angucyclines observed after heterologous expression of re-assembled gre cluster. Therefore, it was concluded that mutation in greN is silent. As all other mutated enzymes/proteins are acting on the later stages of biosynthesis, it is impossible to predict whether they had any impact on the protein function. Nevertheless, it would explain why co-expression of the native greM2 could not force grecocycline biosynthesis. Additionally, no mutations have been identified in any of the two regulatory genes, thereby GreR1 and GreR2 probably do not impair heterologous expression of pGRE.

In summary, TAR method is an efficient and rapid approach for assembly and re-assembly of large DNA fragments into entire biosynthetic gene cluster and its heterologous expression, although the PCR derived mutations should be taken into account. All experimental evidence suggests that the re-assembled gene cluster is indeed involved in the biosynthesis of grecocycline in the native producer and several unique enzymes (especially GreGT4 and the sugar biosynthetic proteins) may find their application in the derivatization of known active angucyclines via combinatorial biosynthesis.

\section{Supporting Information}

S1 Fig. Comparison of isolated tetrangulol and a standard. A-High-resolution mass spectra of the tetrangulol standard, B-UV/Vis spectrum of the tetrangulol standard, C-High-resolution mass spectra of an isolated tetrangulol, $\mathrm{D}-\mathrm{UV} / \mathrm{V}$ is spectrum of an isolated tetrangulol. (TIF)

S2 Fig. Comparison of isolated rabelomycin and a standard. A-High-resolution mass spectra of the rabelomycin standard, B-UV/Vis spectrum of the rabelomycin standard, C-Highresolution mass spectra of an isolated rabelomycin, $\mathrm{D}-\mathrm{UV} / \mathrm{Vis}$ spectrum of an isolated rabelomycin.

S1 Table. Oligonucleotides used in this study. (PDF)

S2 Table. Oligonucleotides used for sequencing pGRE. (PDF)

S3 Table. PCR conditions used in this study. (PDF) 


\section{Acknowledgments}

This work was supported by the ERC starting grant EXPLOGEN No. 281623 to AL.

\section{Author Contributions}

Conceived and designed the experiments: OB OS SZ AL. Performed the experiments: OB OS. Analyzed the data: OB OS SZ AL. Contributed reagents/materials/analysis tools: OB OS SZ AL. Wrote the paper: OB OS SZ AL.

\section{References}

1. Sánchez S, Demain AL. Antibiotics: Current Innovations and Future Trends: Caister Academic Press; 2015.

2. Green MR, Sambrook J. Molecular cloning: a laboratory manual. 4th ed. Cold Spring Harbor, N.Y.: Cold Spring Harbor Laboratory Press; 2012.

3. Sambrook J, Fritsch E.F., and Maniatis T. Molecular Cloning: A Laboratory Manual. 2 ed. Cold Spring Harbor, New York.: Cold Spring Harbor Laboratory Press 1989.

4. Zhang L, Zhao G, Ding X. Tandem assembly of the epothilone biosynthetic gene cluster by in vitro sitespecific recombination. Scientific reports. 2011; 1:141. Epub 2012/02/23. doi: 10.1038/srep00141 PMID: 22355658; PubMed Central PMCID: PMC3216622.

5. Wexler M, Bond PL, Richardson DJ, Johnston AW. A wide host-range metagenomic library from a waste water treatment plant yields a novel alcohol/aldehyde dehydrogenase. Environmental microbiology. 2005; 7(12):1917-26. Epub 2005/11/29. doi: 10.1111/j.1462-2920.2005.00854.x PMID: 16309390.

6. Aakvik T, Degnes KF, Dahlsrud R, Schmidt F, Dam R, Yu L, et al. A plasmid RK2-based broad-hostrange cloning vector useful for transfer of metagenomic libraries to a variety of bacterial species. FEMS microbiology letters. 2009; 296(2):149-58. Epub 2009/05/23. doi: 10.1111/j.1574-6968.2009.01639.x PMID: 19459950.

7. Bates $S$, Cashmore $A M$, Wilkins BM. IncP plasmids are unusually effective in mediating conjugation of Escherichia coli and Saccharomyces cerevisiae: involvement of the tra2 mating system. Journal of bacteriology. 1998; 180(24):6538-43. Epub 1998/12/16. PMID: 9851996; PubMed Central PMCID: PMC107755.

8. Yamanaka K, Reynolds KA, Kersten RD, Ryan KS, Gonzalez DJ, Nizet V, et al. Direct cloning and refactoring of a silent lipopeptide biosynthetic gene cluster yields the antibiotic taromycin A. Proceedings of the National Academy of Sciences of the United States of America. 2014; 111(5):1957-62. Epub 2014/01/23. doi: 10.1073/pnas.1319584111 PMID: 24449899; PubMed Central PMCID: PMC3918841.

9. Bonet B, Teufel R, Crusemann M, Ziemert N, Moore BS. Direct Capture and Heterologous Expression of Salinispora Natural Product Genes for the Biosynthesis of Enterocin. Journal of natural products. 2014. Epub 2014/11/11. doi: 10.1021/np500664q PMID: 25382643.

10. Ross AC, Gulland LE, Dorrestein PC, Moore BS. Targeted Capture and Heterologous Expression of the Pseudoalteromonas Alterochromide Gene Cluster in Escherichia coli Represents a Promising Natural Product Exploratory Platform. ACS synthetic biology. 2014. Epub 2014/08/21. doi: 10.1021/ sb500280q PMID: 25140825.

11. Kim JH, Feng Z, Bauer JD, Kallifidas D, Calle PY, Brady SF. Cloning large natural product gene clusters from the environment: piecing environmental DNA gene clusters back together with TAR. Biopolymers. 2010; 93(9):833-44. Epub 2010/06/26. doi: 10.1002/bip.21450 PMID: 20577994; PubMed Central PMCID: PMC2895911.

12. Larionov V, Kouprina N, Graves J, Resnick MA. Highly selective isolation of human DNAs from rodenthuman hybrid cells as circular yeast artificial chromosomes by transformation-associated recombination cloning. Proceedings of the National Academy of Sciences of the United States of America. 1996; 93(24):13925-30. Epub 1996/11/26. PMID: 8943037; PubMed Central PMCID: PMC19470.

13. Lee NC, Larionov V, Kouprina N. Highly efficient CRISPR/Cas9-mediated TAR cloning of genes and chromosomal loci from complex genomes in yeast. Nucleic acids research. 2015; 43(8):e55. doi: 10. 1093/nar/gkv112 PMID: 25690893; PubMed Central PMCID: PMC4417148.

14. Luzhetskyy A, Fedoryshyn M, Gromyko O, Ostash B, Rebets $Y$, Bechthold A, et al. IncP plasmids are most effective in mediating conjugation between Escherichia coli and streptomycetes. Genetika. 2006; 42(5):595-601. Epub 2006/07/01. PMID: 16808239. 
15. Oxender DL, Anderson JJ, Daniels CJ, Landick R, Gunsalus RP, Zurawski G, et al. Structural and functional analysis of cloned DNA containing genes responsible for branched-chain amino acid transport in Escherichia coli. Proceedings of the National Academy of Sciences of the United States of America. 1980; 77(3):1412-6. Epub 1980/03/01. PMID: 6445555; PubMed Central PMCID: PMC348505.

16. Gietz RD, Woods RA. Transformation of yeast by lithium acetate/single-stranded carrier DNA/polyethylene glycol method. Methods Enzymol. 2002; 350:87-96. Epub 2002/06/21. PMID: 12073338.

17. Blin K, Medema MH, Kazempour D, Fischbach MA, Breitling R, Takano E, et al. antiSMASH 2.0-a versatile platform for genome mining of secondary metabolite producers. Nucleic acids research. 2013; 41 (Web Server issue):W204-12. Epub 2013/06/06. doi: 10.1093/nar/gkt449 PMID: 23737449; PubMed Central PMCID: PMC3692088.

18. Paululat TK, Hausmann A., Karagouni H., Zinecker A. D., Imhoff H., Fiedler J. F., P H.. Grecocyclines: New Angucyclines from Streptomyces sp. Acta 1362. European Journal of Organic Chemistry. 2010; 2010(12):2344-50. doi: 10.1002/ejoc.201000054

19. Erb A, Luzhetskyy A, Hardter U, Bechthold A. Cloning and sequencing of the biosynthetic gene cluster for saquayamycin $Z$ and galtamycin $B$ and the elucidation of the assembly of their saccharide chains. Chembiochem: a European journal of chemical biology. 2009; 10(8):1392-401. Epub 2009/04/23. doi: 10.1002/cbic.200900054 PMID: 19384899.

20. Westrich L, Domann S, Faust B, Bedford D, Hopwood DA, Bechthold A. Cloning and characterization of a gene cluster from Streptomyces cyanogenus $\mathrm{S} 136$ probably involved in landomycin biosynthesis. FEMS microbiology letters. 1999; 170(2):381-7. Epub 1999/02/06. PMID: 9933932.

21. Luzhetskyy A, Fedoryshyn M, Durr C, Taguchi T, Novikov V, Bechthold A. Iteratively acting glycosyltransferases involved in the hexasaccharide biosynthesis of landomycin A. Chemistry \& biology. 2005; 12(7):725-9. Epub 2005/07/26. doi: 10.1016/j.chembiol.2005.05.008 PMID: 16039521.

22. Toda S, Yamamoto S, Tenmyo O, Tsuno T, Hasegawa T, Rosser M, et al. A new neuritogenetic compound BU-4514N produced by Microtetraspora sp. The Journal of antibiotics. 1993; 46(6):875-83. Epub 1993/06/01. PMID: 8344867.

23. Trefzer A, Hoffmeister D, Kunzel E, Stockert S, Weitnauer G, Westrich L, et al. Function of glycosyltransferase genes involved in urdamycin A biosynthesis. Chemistry \& biology. 2000; 7(2):133-42. Epub 2000/02/09. PMID: 10662691.

24. Zhang X, Alemany LB, Fiedler HP, Goodfellow M, Parry RJ. Biosynthetic investigations of lactonamycin and lactonamycin z: cloning of the biosynthetic gene clusters and discovery of an unusual starter unit. Antimicrobial agents and chemotherapy. 2008; 52(2):574-85. Epub 2007/12/12. doi: 10.1128/AAC. 00717-07 PMID: 18070976; PubMed Central PMCID: PMC2224763.

25. Itou $\mathrm{H}$, Tanaka I. The OmpR-family of proteins: Insight into the tertiary structure and functions of twocomponent regulator proteins. Journal of Biochemistry. 2001; 129(3):343-50. ISI:000167485600002. PMID: 11226872

26. Rebets Y, Ostash B, Luzhetskyy A, Hoffmeister D, Brana A, Mendez C, et al. Production of landomycins in Streptomyces globisporus 1912 and $S$ cyanogenus $S 136$ is regulated by genes encoding putative transcriptional activators. FEMS microbiology letters. 2003; 222(1):149-53. Epub 2003/05/22. PMID: 12757959.

27. Gromyko O, Rebets Y, Ostash B, Luzhetskyy A, Fukuhara M, Bechthold A, et al. Generation of Streptomyces globisporus SMY622 strain with increased landomycin E production and it's initial characterization. The Journal of antibiotics. 2004; 57(6):383-9. Epub 2004/08/25. PMID: 15323127.

28. Rebets $Y V$, Ostash BO, Fukuhara M, Nakamura T, Fedorenko VO. Expression of the regulatory protein Lndl for landomycin E production in Streptomyces globisporus 1912 is controlled by the availability of tRNA for the rare UUA codon. FEMS microbiology letters. 2006; 256(1):30-7. Epub 2006/02/21. doi: 10.1111/j.1574-6968.2005.00087.x PMID: 16487316.

29. Chang $A C$, Cohen $S N$. Construction and characterization of amplifiable multicopy DNA cloning vehicles derived from the P15A cryptic miniplasmid. Journal of bacteriology. 1978; 134(3):1141-56. Epub 1978/ 06/01. PMID: 149110; PubMed Central PMCID: PMC222365.

30. Sekurova ON, Brautaset T, Sletta H, Borgos SE, Jakobsen MO, Ellingsen TE, et al. In vivo analysis of the regulatory genes in the nystatin biosynthetic gene cluster of Streptomyces noursei ATCC 11455 reveals their differential control over antibiotic biosynthesis. Journal of bacteriology. 2004; 186 (5):1345-54. Epub 2004/02/20. PMID: 14973031; PubMed Central PMCID: PMC344421.

31. Gibson DG, Young L, Chuang RY, Venter JC, Hutchison CA 3rd, Smith HO. Enzymatic assembly of DNA molecules up to several hundred kilobases. Nature methods. 2009; 6(5):343-5. Epub 2009/04/ 14. doi: $10.1038 /$ nmeth.1318 PMID: 19363495.

32. Podkovyrov SM, Larson TJ. A new vector-host system for construction of lacZ transcriptional fusions where only low-level gene expression is desirable. Gene. 1995; 156(1):151-2. Epub 1995/04/14. PMID: 7737510. 
33. Kouprina $\mathrm{N}$, Larionov $\mathrm{V}$. Selective isolation of genomic loci from complex genomes by transformationassociated recombination cloning in the yeast Saccharomyces cerevisiae. Nat Protoc. 2008; 3(3):3717. Epub 2008/03/08. doi: 10.1038/nprot.2008.5 PMID: 18323808.

34. Zaburannyi N, Rabyk M, Ostash B, Fedorenko V, Luzhetskyy A. Insights into naturally minimised Streptomyces albus J1074 genome. Bmc Genomics. 2014; 15. Artn 97 doi: 10.1186/1471-2164-15-97 ISI:000332576900001.

35. Zhu L, Ostash B, Rix U, Nur EAM, Mayers A, Luzhetskyy A, et al. Identification of the function of gene IndM2 encoding a bifunctional oxygenase-reductase involved in the biosynthesis of the antitumor antibiotic landomycin E by Streptomyces globisporus 1912 supports the originally assigned structure for landomycinone. J Org Chem. 2005; 70(2):631-8. Epub 2005/01/18. doi: 10.1021/jo0483623 PMID: 15651811; PubMed Central PMCID: PMC2884283.

36. Faust B, Hoffmeister D, Weitnauer G, Westrich L, Haag S, Schneider P, et al. Two new tailoring enzymes, a glycosyltransferase and an oxygenase, involved in biosynthesis of the angucycline antibiotic urdamycin A in Streptomyces fradiae Tu2717. Microbiology. 2000; 146 (Pt 1):147-54. Epub 2000/ 02/05. PMID: 10658661.

37. Berdy J. Bioactive microbial metabolites. The Journal of antibiotics. 2005; 58(1):1-26. Epub 2005/04/ 09. doi: 10.1038/ja.2005.1 PMID: 15813176.

38. Bentley SD, Chater KF, Cerdeno-Tarraga AM, Challis GL, Thomson NR, James KD, et al. Complete genome sequence of the model actinomycete Streptomyces coelicolor A3(2). Nature. 2002; 417 (6885):141-7. Epub 2002/05/10. doi: 10.1038/417141a PMID: 12000953.

39. Kouprina N, Larionov V. TAR cloning: insights into gene function, long-range haplotypes and genome structure and evolution. Nature reviews Genetics. 2006; 7(10):805-12. doi: 10.1038/nrg1943 PMID: 16983376.

40. Luzhetskyy A, Taguchi T, Fedoryshyn M, Durr C, Wohlert SE, Novikov V, et al. LanGT2 Catalyzes the First Glycosylation Step during landomycin A biosynthesis. Chembiochem: a European journal of chemical biology. 2005; 6(8):1406-10. Epub 2005/06/25. doi: 10.1002/cbic.200500018 PMID: 15977274.

41. Rix U, Wang C, Chen Y, Lipata FM, Remsing Rix LL, Greenwell LM, et al. The oxidative ring cleavage in jadomycin biosynthesis: a multistep oxygenation cascade in a biosynthetic black box. Chembiochem: a European journal of chemical biology. 2005; 6(5):838-45. Epub 2005/03/19. doi: 10.1002/cbic. 200400395 PMID: 15776503.

42. Lombo F, Abdelfattah MS, Brana AF, Salas JA, Rohr J, Mendez C. Elucidation of oxygenation steps during oviedomycin biosynthesis and generation of derivatives with increased antitumor activity. Chembiochem: a European journal of chemical biology. 2009; 10(2):296-303. Epub 2008/11/07. doi: 10 1002/cbic.200800425 PMID: 18988223; PubMed Central PMCID: PMC2661761.

43. Palmu K, Ishida K, Mantsala $P$, Hertweck $C$, Metsa-Ketela M. Artificial reconstruction of two cryptic angucycline antibiotic biosynthetic pathways. Chembiochem: a European journal of chemical biology. 2007; 8(13):1577-84. Epub 2007/07/27. doi: 10.1002/cbic.200700140 PMID: 17654627.

44. Kharel MK, Pahari P, Shaaban KA, Wang G, Morris C, Rohr J. Elucidation of post-PKS tailoring steps involved in landomycin biosynthesis. Organic \& biomolecular chemistry. 2012; 10(21):4256-65. Epub 2012/03/29. doi: 10.1039/c2ob07171a PMID: 22454092.

45. Kharel MK, Rohr J. Delineation of gilvocarcin, jadomycin, and landomycin pathways through combinatorial biosynthetic enzymology. Current opinion in chemical biology. 2012; 16(1-2):150-61. Epub 2012/ 04/03. doi: 10.1016/j.cbpa.2012.03.007 PMID: 22465094; PubMed Central PMCID: PMC3820281.

46. Ajikumar PK, Xiao WH, Tyo KE, Wang Y, Simeon F, Leonard E, et al. Isoprenoid pathway optimization for Taxol precursor overproduction in Escherichia coli. Science. 2010; 330(6000):70-4. doi: 10.1126/ science.1191652 PMID: 20929806; PubMed Central PMCID: PMC3034138.

47. Du J, Yuan Y, Si T, Lian J, Zhao H. Customized optimization of metabolic pathways by combinatorial transcriptional engineering. Nucleic acids research. 2012; 40(18):e142. doi: 10.1093/nar/gks549 PMID: 22718979; PubMed Central PMCID: PMC3467037.

48. Han L, Yang K, Kulowski K, Wendt-Pienkowski E, Hutchinson CR, Vining LC. An acyl-coenzyme A carboxylase encoding gene associated with jadomycin biosynthesis in Streptomyces venezuelae ISP5230. Microbiology. 2000; 146 (Pt 4):903-10. Epub 2000/04/28. PMID: 10784049.

49. Metsa-Ketela $\mathrm{M}$, Ylihonko $\mathrm{K}$, Mantsala $\mathrm{P}$. Partial activation of a silent angucycline-type gene cluster from a rubromycin beta producing Streptomyces sp. PGA64. The Journal of antibiotics. 2004; 57 (8):502-10. Epub 2004/11/02. PMID: 15515887. 